OPEN ACCESS

Edited by:

Juel Jarani,

Sports University of Tirana, Albania

Reviewed by:

Selcuk Akpinar,

Nevşehir Haci Bektaş Veli

University, Turkey

Predrag R. Bozic,

Serbian Institute of Sport and Sports

Medicine (SISSM), Serbia

*Correspondence:

Bojan Masanovic

bojanma@ucg.ac.me

Specialty section:

This article was submitted to

Children and Health,

a section of the journal

Frontiers in Public Health

Received: 25 September 2020

Accepted: 21 October 2020

Published: 06 November 2020

Citation:

Popovic S, Masanovic B,

Martinovic S, Bjelica D and

Gardasevic J (2020) Trajectories in

Body Height, Body Weight, BMI, and

Nutrition Status From 1979 to 1987: A

Measurement-Based Analysis of

15,717 Male Adolescents From the

Capital City of Montenegro.

Front. Public Health 8:610358.

doi: 10.3389/fpubh.2020.610358

\section{Trajectories in Body Height, Body Weight, BMI, and Nutrition Status From 1979 to 1987: A Measurement-Based Analysis of 15,717 Male Adolescents From the Capital City of Montenegro}

\author{
Stevo Popovic ${ }^{1,2}$, Bojan Masanovic ${ }^{1,2 *}$, Srdja Martinovic ${ }^{3,4}$, Dusko Bjelica ${ }^{1,2}$ and \\ Jovan Gardasevic ${ }^{1,2}$ \\ ${ }^{1}$ Faculty for Sport and Physical Education, University of Montenegro, Niksic, Montenegro, ${ }^{2}$ Montenegrin Sports Academy, \\ Podgorica, Montenegro, ${ }^{3}$ Faculty of Law, University of Montenegro, Podgorica, Montenegro, ${ }^{4}$ Ministry of Defence, \\ Government of Montenegro, Podgorica, Montenegro
}

Introduction and Objective: This study aimed to consolidate body height and body weight, as well as the body mass index and nutrition status data of the entire male population of adolescents from Podgorica, the capital of Montenegro, in order to estimate trajectories in ahead mentioned variables from 1979 to 1987.

Methods: The sample includes 15,717 male adolescents divided into nine groups according to their year of birth. The sample of variables includes body height, body weight, and body mass index, as well as nutrition status, which was presented based on BMl standardized categories (underweight, normal weight, pre-obese, obese). The descriptive statistics were expressed as a mean and standard deviation for each variable, while post-hoc test with ANOVA were employed to explore differences between the means.

Results and Discussion: This study did not find significant differences in the body proportions of the measured group of subjects during the observed period, but some descriptive differences were observed that might be of interest for further analysis, especially when it comes to nutritional status.

Conclusions: The novelty and the original contribution of this study is reflected in the fact that descriptive data from the second half of the 20th century have been published, which can significantly help to follow the secular trend of one of the tallest nations in the world from the beginning of the 20th century-Montenegro-which has specific body proportions.

Keywords: anthropometry, secular trend, body proportions, youngsters, Montenegro 


\section{INTRODUCTION}

Trends in men's body height have been monitored and analyzed around the world for a very long time, almost 250 years $(1,2)$, and have been attracting a great deal of attention from people all over the world. In recent decades, in most industrialized countries, gradual progressive changes in mean body height values can be observed (1). Average adult body height has dramatically increased in Montenegro too $(3,4)$. The cause of this might be much better lifestyles adopted by the population, and it might be the result of better living conditions and improved nutritional, hygienic, economic, and health status (5-7). However, there is a lack of data within this population, which will be further elaborated. Namely, it is necessary to mention that Montenegro is located on the slopes of the Dinaric Alps, an area that has historically been recognized as a habitat of above-average tall people [cited in (4)]. The unusual height of Montenegrins was first observed by Robert Ehrich, measuring the male inhabitants of this area in the early 20th century $(8,9)$. The following studies that estimate the average body height of Montenegrins appear at the beginning of the 21st century, and all of them confirm that Montenegrins are one of the tallest nations in the world (10-14). Among the above-mentioned studies, a lack of record-keeping is noticeable. There is a multi-decade gap of quality data, which made it impossible to conduct a precise analysis of the factors that influenced the mentioned trends. This type of data is available throughout Europe and the rest of the world, which allows a detailed analysis of the secular trends. A great example can be found in the Netherlands where the tallest population nowadays live. Dutch central government created a system of key registers based on digital data, collected by government organizations for administrative purposes and databases are available to scientists on the basis of which they claim with certainty that their people have become taller and heavier since 1981 and accurately determine the secular trend. However, the ahead mentioned gap in Montenegro will be partly alleviated by this study and briefly explained and compared to other nation in the discussion section.

Trends in men's body weight have also shown a tendency to increase in previous studies (15-19), which is a logical consequence because the increase in size and magnitude must be accompanied by an increase in body weight but the accumulation of excess adipose tissue is the cause as well. However, body weight is not a variable that was analyzed by Montenegrin scientists very much. Although the body weight and body mass indexes, as well as nutritional status, are very important variables in many settings, organized national surveys were not conducted in Montenegro. Each set of data that can be accessed within the Montenegrin population from the 20th century is beneficial for further public health investigations. Although several studies evaluate changes in body height and monitor underweight, overweight, or obesity problems in school children (not in adolescents), very few monitor average body weight and body mass index (BMI) changes for a longer period; such trend studies have only been emerging recently (20-22). However, they are limited to local samples and do not include a sufficient number of respondents to generalize the conclusions. For this reason, in anticipation of a new statistics act that would stipulate that reduce the administrative burden to a minimum and allow scientists to access government key registers for statistical purposes, the Ministry of Defense and the University of Montenegro started a joint project to digitalize all the available data from the old archives of the Yugoslav People's Army, mostly because each male adolescent had to pass a medical examination, and the results were stored in their medical records.

As one of the first outcomes of this project, this study brings together the body height, body weight, and body mass index data of an entire young male population of the capital of Montenegro, Podgorica, which is the largest city in the country, including almost $30 \%$ of the nation's population, to evaluate the possible trends from 1979 to 1987, for the purpose of collecting information on possible acceleration, as well as the trajectories (changes) of nutrition status in adolescence.

\section{METHODS}

The population of this retrospective cross-sectional study contains the entire male population of the capital city of Montenegro, Podgorica, measured during mandatory medical examinations to test their ability for military service. Most future recruits underwent this examination before they were 18 years old, but military service could be postponed until the age of 27 , so some of the future recruits had their medical examinations later, which increased the average age in each generation. However, the detailed analyses in the results section described it precisely.

In the period from 20 April 1979 to 1 July 1987, 16,401 future recruits of the Yugoslav People's Army with permanent residence in Podgorica underwent this examination, but male adolescents that were born in $1957(n=108), 1958(n=115), 1959(n=$ $156)$, and $1960(n=305)$ were excluded from the analysis because their numbers were not large enough to represent (and reliably describe) an entire generation. Consequently, the analyzed data in this study covers the sample of 15,717 future recruits (17.93 \pm 64 years) divided into nine groups: 1,326 subjects that were born in 1961 (18.54 \pm 95 years), 1,927 in 1962 (18.22 \pm 49 years), 1,859 in 1963 (17.92 \pm 69 years), 1,021 in 1964 (17.77 \pm 77 years), 1,822 in 1965 (17.82 \pm 7 years), 2,346 in 1966 (17.91 \pm 62 years), 1,634 in 1967 (17.88 \pm 5 years), 1,897 in 1968 (17.72 \pm 31 years), and 1,885 in 1969 ( $17.71 \pm 17$ years).

Anthropometric measurement was implemented in medical infirmaries, and subjects accessed the procedure in their underwear. From the sample measures that were collected for this research, body height and body weight were isolated; the body mass index is calculated using them. For body height and body weight assessment, a medical scale with moving weights with a stadiometer was used. Anthropometrical measurement was implemented by respecting the basic rules and principles of the International Biological Program (IBP). The body mass index was calculated based on the protocol handbook for physical form assessment connected to health (23), while the nutrition status was presented based on BMI standardized categories (underweight, normal weight, pre-obese, and obese) (24). 
TABLE 1 | Descriptive and Comparative Data of Male Adolescents from the Capital City of Montenegro enrolled in the study.

\begin{tabular}{|c|c|c|c|c|}
\hline \multirow[b]{2}{*}{$\begin{array}{l}\text { Year of Birth } \\
\text { (Number of Subjects) }\end{array}$} & \multicolumn{4}{|c|}{ Mean \pm SD } \\
\hline & $\begin{array}{c}\text { Age } \\
\text { (years) }\end{array}$ & $\begin{array}{l}\text { Body Height } \\
\text { (cm) }\end{array}$ & $\begin{array}{l}\text { Body Weight } \\
\text { (kg) }\end{array}$ & $\begin{array}{l}\text { Body Mass } \\
\text { Index }\left(\mathbf{k g} / \mathbf{m}^{2}\right)\end{array}$ \\
\hline $1961(N=1,326)$ & $18.54 \pm 0.95$ & $177.12 \pm 6.98$ & $68.70 \pm 8.93$ & $21.86 \pm 2.24$ \\
\hline $1962(N=1,927)$ & $18.22 \pm 0.49$ & $177.71 \pm 6.80$ & $68.74 \pm 8.82$ & $21.73 \pm 2.16$ \\
\hline $1963(N=1,859)$ & $17.92 \pm 0.69$ & $177.74 \pm 6.89$ & $68.46 \pm 9.50$ & $21.64 \pm 2.48$ \\
\hline $1964(N=1,021)$ & $17.77 \pm 0.77$ & $176.64 \pm 7.37$ & $67.35 \pm 9.16$ & $21.57 \pm 2.48$ \\
\hline $1965(N=1,822)$ & $17.82 \pm 0.70$ & $176.57 \pm 6.88$ & $68.13 \pm 9.51$ & $21.82 \pm 2.52$ \\
\hline $1966(N=2,346)$ & $17.91 \pm 0.62$ & $177.46 \pm 6.77$ & $68.45 \pm 9.11$ & $21.71 \pm 2.50$ \\
\hline $1967(N=1,634)$ & $17.88 \pm 0.50$ & $177.27 \pm 7.25$ & $68.79 \pm 9.04$ & $21.87 \pm 2.39$ \\
\hline $1968(N=1,897)$ & $17.72 \pm 0.31$ & $176.73 \pm 7.06$ & $68.33 \pm 9.29$ & $21.86 \pm 2.27$ \\
\hline $1969(N=1,885)$ & $17.71 \pm 0.17$ & $177.12 \pm 6.95$ & $69.01 \pm 9.64$ & $21.97 \pm 2.59$ \\
\hline $1961-1969(N=15,717)$ & $17.93 \pm 0.64$ & $177.19 \pm 6.98$ & $68.49 \pm 9.26$ & $21.79 \pm 2.45$ \\
\hline
\end{tabular}

No statistically significant difference between study groups were found.

The data obtained in the research were processed using SPSS 20.0 software (Chicago, IL, USA). The descriptive statistics were expressed as a mean and standard deviation for each variable, while post-hoc test with ANOVA were employed to explore differences between the means.

\section{RESULTS}

An analysis of the average body height, body mass, and body mass index of young male subjects is shown in Table $\mathbf{1}$.

The average body height of the overall sample of male subjects was $177.19 \pm 6.98 \mathrm{~cm}$. The tallest group were subjects that were born in 1963 (177.74 \pm 6.89$)$, while shorter ones were subjects that were born in $1965(176.57 \pm 6.88)$. The average body weight of the overall sample of male subjects was $68.49 \pm 9.29 \mathrm{~kg}$, while the heaviest subjects were those that were born in 1969 (69.01 $\pm 9.64)$, and the least heavy were those born in 1964 (67.35 \pm 9.16 ). The average body mass index of the overall sample of male subjects was $21.79 \pm 2.45 \mathrm{~kg} / \mathrm{m}^{2}$, while the highest values were among subjects that were born in 1969 (21.97 \pm $2.59 \mathrm{~kg} / \mathrm{m}^{2}$ ), and the lowest values had those that were born in $1964\left(21.57 \pm 2.48 \mathrm{~kg} / \mathrm{m}^{2}\right)$. The post-hoc test with ANOVA were employed to explore differences between the means and no statistically significant difference between study groups were found.

From Table 2, it can be observed that, in the overall sample of subjects, $6 \%$ were underweight, $85.16 \%$ were normal weight, $8.11 \%$ were pre-obese, and $0.74 \%$ were obese. The highest percentage of underweight is in the group of subjects that were born in $1964(8.74 \%)$, while the lowest percentage is in the group of subjects that were born in 1961 (3.77\%). The highest percentage of subjects with normal body weight is in the group of subjects that were born in 1961 (88.99\%), while the lowest percentage is in those that were born in 1968 (82.24\%). The highest percentage of pre-obesity is in the group of subjects that were born in $1968(10.33 \%)$, while the lowest percentage is in those that were born in 1963 (6.13\%). Lastly, the highest percentage of obesity is in the group of subjects that were born in $1963(1.08 \%)$, while the lowest percentage is in those that were born in $1962(0.21 \%)$.

\section{DISCUSSION}

This study aimed to make a specific contribution in an attempt to resolve the centuries-old dilemma regarding the specifics of the body composition of Montenegrins. It was known that Montenegrins were the tallest nation in the world at the beginning of the 20th century $(3,8,10)$ and that this fact has changed little in the last 100 years; Montenegrins were the second tallest nation at the beginning of the 21 st century (4), just behind the Dutch (25). However, it remains unknown whether the growth trend was continuous or whether certain periods particularly influenced the growth and development of Montenegrins, and there are no scientific studies that would aid in answering this research question.

A deeper analysis and knowledge of specific growth and development trends would significantly help, first, in explaining the specifics of body height and other indicators of body composition, as well as providing a significant context for the further assessment of growth and development of Montenegrins in the future. Nevertheless, the answer could not be determined that far, and it will not be after the publication of this study. However, this study will, to a certain measure, help to reduce the existing gap and initiate the need for studies with relevant data to emerge that scientists could rely on in the future.

As a large number of scientists believe that the secular trend has not concluded in this population, the significance of this issue is gaining in importance, not only among physical anthropologists, but also among researchers from other related fields, because body height, as well other parameters that describe human body composition, are very important in many areas of human life (26). For example, from the fact the impact of better material living standards make people taller, the body height became a relevant indirect measure for living conditions in the periods for which little or no other data is available. 
TABLE 2 | The Nutrition Status of Male Adolescents from the Capital City of Montenegro enrolled in the study.

\begin{tabular}{|c|c|c|c|c|c|c|c|c|c|}
\hline \multirow[t]{2}{*}{ Year of Birth } & \multirow{2}{*}{$\begin{array}{c}\text { Total } \\
\mathbf{N}\end{array}$} & \multicolumn{2}{|c|}{ Underweight } & \multicolumn{2}{|c|}{ Normal weight } & \multicolumn{2}{|c|}{ Pre-obese } & \multicolumn{2}{|c|}{ Obese } \\
\hline & & $N$ & $\%$ & $N$ & $\%$ & $N$ & $\%$ & $N$ & $\%$ \\
\hline 1961 & $(n=1,326)$ & 50 & 3.77 & 1,180 & 88.99 & 88 & 6.64 & 8 & 0.60 \\
\hline 1962 & $(n=1,927)$ & 94 & 4.88 & 1,705 & 88.48 & 124 & 6.43 & 4 & 0.21 \\
\hline 1963 & $(n=1,859)$ & 130 & 6.99 & 1,595 & 85.80 & 114 & 6.13 & 20 & 1.08 \\
\hline 1964 & $(n=1,021)$ & 80 & 7.84 & 857 & 83.94 & 78 & 7.64 & 6 & 0.59 \\
\hline 1965 & $(n=1,822)$ & 124 & 6.81 & 1,525 & 83.70 & 158 & 8.67 & 15 & 0.82 \\
\hline 1966 & $(n=2,346)$ & 157 & 6.69 & 1,990 & 84.83 & 176 & 7.50 & 23 & 0.98 \\
\hline 1967 & $(n=1,634)$ & 77 & 4.71 & 1,392 & 85.19 & 156 & 9.55 & 9 & 0.55 \\
\hline 1968 & $(n=1,897)$ & 127 & 6.69 & 1,560 & 82.24 & 196 & 10.33 & 14 & 0.74 \\
\hline 1969 & $(n=1,885)$ & 104 & 5.52 & 1,580 & 83.82 & 184 & 9.76 & 17 & 0.90 \\
\hline 1961-1969 & $(n=15,717)$ & 943 & 6.00 & 13,384 & 85.16 & 1,274 & 8.11 & 116 & 0.74 \\
\hline
\end{tabular}

The fact that Montenegrins have grown by $6.36 \mathrm{~cm}$ in a little over 100 years (3), and that it is not known within what dynamics this growth took place, any study that would fill the gap in the database is welcome. The best comparative example is the Netherlands where the tallest people currently live but also where the secular trend is over. Dutch have grown by $14.37 \mathrm{~cm}$ in a little over 100 years $(2,25)$, much more than Montenegrins. So, if hypotheses are right that the secular trend in Montenegro is not over, there is a real possibility that Montenegrins will once again become the tallest nation in the world as soon as they reach the maximum body height.

One of the most important steps in proving the above claim is the capital city, which is partially, perhaps the most important part for analysis, since $30 \%$ of the entire Montenegrin population lives in it today, while three other Montenegrin cities have been processed too, namely Cetinje, Niksic, and Bar (20-22). The results of the research in the first two mentioned cities, which together with Podgorica, make up the central region of Montenegro, can already be very interesting in interpreting the obtained results, while the results from other Montenegrin cities are expected shortly, since the work on the digitization of the entire national data remains in process. It is interesting to note that particular attention will be paid to the results that will be obtained in research on the body composition of future recruits in cities across the northern and southern regions (at present only Bar is available), because it is generally known that there are traditional socioeconomic and demographic differences between people in these regions (27).

Nevertheless, it is necessary to return to the discussion of the results of this study, in which the entire population of the capital of Montenegro is processed. In the 1980s, Podgorica was, demographically speaking, a completely different city. At that time, there were 132,290 inhabitants in Podgorica $22.64 \%$ of the total population of Montenegro), while today's Podgorica officially has 185,937 inhabitants, which represents $29.99 \%$ of the total population $(28,29)$. Changes in the number of inhabitants are conditioned by the constant development of the city in recent decades, and migrations to Podgorica were directed, primarily from rural areas of Montenegro, but also from smaller cities, as Podgorica offered many more opportunities to achieve a better lifestyle, both adult and younger population, as a secondary school and university center. It is worth noting that the increase of more than 50,000 inhabitants represents a significant figure for a small population such as Montenegro, while there is a suspicion that this number is even higher, as there are many citizens of the capital whose official residences are still in their home towns, since they are not significantly geographically dislocated.

The population of today's capital could, methodologically speaking, almost be a representative sample of the entire Montenegrin population, given that Podgorica is inhabited by people from all parts of Montenegro. However, the study in which Popovic (3) processed body height, primarily the entire population $(183.36 \mathrm{~cm})$, then the region (north $=183.01 \mathrm{~cm}$; middle $=183.58 \mathrm{~cm}$; south $=182.55 \mathrm{~cm}$ ), but also Montenegrin cities (Podgorica $=182.04 \mathrm{~cm}$ ), clearly indicates that huge gap reached over several decades do not allow the data from Podgorica to be used as a representative sample of the Montenegrin population when it comes to body height. Also, the results from Popovic's study (3) cannot even be compared with the data collected from the capital city in the 1980s, due to the large migrations from rural areas to Podgorica over last few decades. However, it is interesting to discuss the fact that the average body height of Montenegrins from the beginning of the 20th century was $177 \mathrm{~cm}$, while a similar average was determined in the $80 \mathrm{~s}$ in Podgorica $(177.19 \mathrm{~cm})$ that is only $0.19 \mathrm{~cm}$ higher. In contrast, current inhabitants of Podgorica are $182.04 \mathrm{~cm}$ tall, which is about $5 \mathrm{~cm}$ more, and the difference was achieved in a much shorter period. For that reason, the research question again arises as to what influenced such a drastic change: migration, socio-economic factors, or something completely different? The results of some local studies from Niksic, where the citizens of this city were on average $178.58 \mathrm{~cm}$ tall in the $1980 \mathrm{~s}$ (20), or $184.57 \mathrm{~cm}$ at the beginning of the 21st century (3), can aid in answering this question, Cetinje, where the citizens of this city, on average, were $178.38 \mathrm{~cm}$ tall in the 1980s (21), or $181.25 \mathrm{~cm}$ at the beginning of the 21st century (3) and Bar, where the 
citizens of this city were on average $175.82 \mathrm{~cm}$ tall in the $1980 \mathrm{~s}$ (22), and $182.13 \mathrm{~cm}$ at the beginning of the 21 st century in Bar and Ulcinj (3). On the hand, Dutch have grown by $6.50 \mathrm{~cm}$ in since $1981(2,25)$, similarly like Montenegrins in this period of time, and make this research question more complex. However, altogether it leads us to collect a vast amount of data that would reveal the true picture of the growth and development trend of the Montenegrin young male population during the 20th century. Therefore, it is necessary to wait for the results of other ongoing studies in other Montenegrin cities and municipalities and attempt to access data from other periods; it will then be possible to answer much more precisely the research question of this study and related questions regarding the growth trends of the young male Montenegrins.

In contrast, with body weight, body mass index, and nutritional status, the situation is much more complex with regards to previous studies. There are no national studies from the beginning of the 20th century, as is the case with body height, but also in the later period. Studies can be found that are reflected in student papers and research projects done on small samples. In accordance with all the above, the project of the Ministry of Defense and the Faculty of Sports and Physical Education of the University of Montenegro is a crucial activity, primarily introducing us to the body weight, body mass index, and nutritional status of Montenegrins at the national level. This study finds that the average body weight of the citizens of Podgorica in the specified period was $68.49 \pm 9.26 \mathrm{~kg}$, while the body mass index was $21.79 \pm 2.45 \mathrm{~kg} / \mathrm{m}^{2}$. However, as with body height, the same data have already been published from Niksic (Body Weight $=68.56 \pm 8.66$; BMI $=21.48 \pm$ 2.27), Cetinje (Body Weight $=70.16 \pm 9.17$; $\mathrm{BMI}=22.02$ \pm 2.58 ), and Bar (Body Weight $=68.33 \pm 9.73$; BMI $=$ $22.06 \pm 2.58$ ), which significantly opens the way to answer research questions regarding body weight and body mass index, and is still not close to that answer (20-22). However, it is unfortunate that there are no studies that describe Montenegrins as is the case with the Dutch, which can be said that for each additional centimeter in body length, the average Dutchman has become $2.3 \mathrm{~kg}$ heavier between 1981 and 2018 (30), but there is hope that in Montenegro, too, all available data will become digitized and available very soon. From the local perspective, it is interesting to note that the study by Gardasevic et al. (31), although on a small sample, indicates the possibility of a certain positive trend when it comes to body weight, since they found obvious differences in 18-year-old boys from Niksic who weighed an average of $78.5 \mathrm{~kg}$ and their average body mass index was $22.9 \mathrm{~kg} / \mathrm{m}^{2}$, much more in body weight than from the current study, while the body mass index remains in equal values.

Finally, it is worth noting that a large number of studies have examined the nutritional status of the school population in Montenegro, but also amateur and professional athletes, as well as adults; however, the problem that occurs is the same as with the previous variables, primarily because the results obtained cannot be adequately compared for several reasons. In the first place, no data depict the situation before the results obtained in this study (Underweight $=6.00 \%$; Normal weight $=85.16$;
Pre-obese $=8.11$; Obese $=0.74$ ), while methodological principles question the comparison of the results from the 1980s and the results obtained at the beginning of the 21st century, in the same way as described in the part that was dedicated to body height. However, it is necessary to conclude that the nutritional status of the 1980s was at an enviable level and it points out to the fact that adolescents were much more physically active at the time, all the way to the peak reached in the mid-90s (32) and the availability of information technology on a larger scale. Insufficient activity among adolescents is a major concern from the mid-90s up to nowadays, and this kind of studies are more than welcomed.

It is also worth noting that this study has achieved its goal: specifically, it has notably supplemented the existing database regarding the body height, body weight, body mass index, and nutritional status of the Montenegrin male adolescents. A complete sample of the population of the capital gives us a clear picture of what the situation was in Podgorica on this issue in the 1980s. However, although the sample covered the entire male population and filled and existing gap, this study has limitations. The main limitation of this study was to consider the age category of the subjects as the population consists of subject who are younger than 18 years old on average, mostly due to the reason there are assumptions that growth and development does not end at age 18, as it is previously believed, but rather growth and development systematically continues in the torso after 18 years of age (Starc, personal communication), which would ultimately cause an increase in body height. On the other hand, the fundamental methodological limitations do not allow us to compare the existing results from different periods of the 20th and 21st centuries in which they exist in the first place, but also the fact that this study did not include the female population, which is equally interesting for the professional and scientific public. Therefore, the recommendations for future research refer to the further expansion of the existing database, both in the periods where there are individual research studies in certain geographical locations and in the periods when there are none. Although the conclusion of the mentioned project of the Ministry of Defense and the Faculty of Sports and Physical Education of the University of Montenegro will significantly enrich the existing database, further research must treat the female population much more carefully in order to make these results available.

\section{DATA AVAILABILITY STATEMENT}

The raw data supporting the conclusions of this article will be made available by the authors, without undue reservation.

\section{ETHICS STATEMENT}

The studies involving human participants were reviewed and approved by Ministry of Defense. Written informed consent from the participants' legal guardian/next of kin was not required to participate in this study in accordance with the national legislation and the institutional requirements. 


\section{AUTHOR CONTRIBUTIONS}

SP wrote the manuscript, performed analyses, and revised manuscript. BM wrote the manuscript, performed analyses,

\section{REFERENCES}

1. NCD Risk Factor Collaboration. A century of trends in adult human height. eLife. (2016) 5:e13410. doi: 10.7554/eLife.13410

2. NCD Risk Factor Collaboration. Worldwide trends in body-mass index, underweight, overweight, and obesity from 1975 to 2016: a pooled analysis of 2416 population-based measurement studies in 128.9 million children, adolescents, and adults. Lancet. (2017) 390:2627-42. doi: 10.1016/s0140-6736(17)32129-3

3. Popovic S. Local geographical differences in adult body height in Montenegro. Montenegrin J Sports Sci Med. (2017) 6:81-7.

4. Popovic S. Arm-span measurement as an alternative estimation of true height in Montenegrin young adults of both sexes: a national survey. Anthropol Noteb. (2018) 24:53-67.

5. Hauspie RC, Vercauteren M, Susanne C. Secular changes in growth. Horm. Res. (1996) 45:8-17.

6. Gardasevic J, Masanovic B, Arifi F. Relationship between tibia length measurements and standing height: a prospective regional study among adolescents in northern region of Kosovo. Anthropologie. (2019) 57:263-9. doi: 10.26720/anthro.19.08.28.2

7. Masanovic B, Bavcevic T, Prskalo I. Regional differences in adult body height in Kosovo. Montenegrin J Sports Sci Med. (2019) 8:69-76. doi: $10.26773 / \mathrm{mjssm} .190310$

8. Coon C. The Races of Europe New York, NY: Macmillan Publishers (1939).

9. Coon C. The Races of Europe. Westport, CT: Greenwood Press (1975).

10. Bjelica D, Popovic S, Kezunovic M, Petkovic J, Jurak G, Grasgruber P. Body height and its estimation utilizing arm span measurements in montenegrin adults. Anthropol Noteb. (2012) 18:69-83.

11. Milasinovic R, Popovic S, Jaksic D, Vasilejvic I, Bjelica D. Stature and its estimation utilizing arm span measurements in feale adolescents from southern region in Montenegro. Sport Mont. (2016) 14:15-8.

12. Milasinovic R, Popovic S, Matic R, Gardasevic J, Bjelica D. Body Height and its Estimation Utilizing Arm Span Measurements in Male Adolescents from Southern Region in Montenegro. Sport Mont. (2016) 14:21-3.

13. Grasgruber P, Popovic S, Bokuvka D, Davidovic I, Hrebíckova S, Ingrova $\mathrm{P}$, et al. The mountains of giants: an anthropometric survey of male youths in Bosnia and Herzegovina. R Soc Open Sci. (2017) 4:161054. doi: 10.1098/rsos.161054

14. Grasgruber P, Prce S, Stracarova N, Hrazdíra E, Cacek J, Popovic S, et al. The coast of giants: an anthropometric survey of high schoolers on the Adriatic coast of Croatia. PeerJ. (2019) 7:e6598. doi: 10.7717/peerj.6598

15. Bielecki EM, Haas JD, Hulanicka B. Secular changes in the height of Polish schoolboys from 1955 to 1988. Econ. Hum. Biol. (2012) 10:310-7. doi: 10.1016/j.ehb.2011.06.004

16. Cardoso HFV, Caninas M. Secular trends in social class differences of height, weight and BMI of boys from two schools in Lisbon, Portugal (1910-2000). Econ. Hum. Biol. (2010) 8:111-20. doi: 10.1016/j.ehb.2009.04.005

17. Simsek F, Ulukol B, Baskan Gulnar S. The secular trends in height and weight of Turkish school children during 1993-2003. Child Care Health Dev. (2005) 31:441-7. doi: 10.1111/j.1365-2214.2005.00531.x

18. Hosseini M, Taslimi S, Dinarvand P, Jones ME, Mohammad K. Trends in weights, heights, BMI and comparison of their differences in urban and rural areas for Iranian children and adolescents 2-18-year-old between 1990-1991 and 1999. Child Care Health Dev. (2010) 36:858-67. doi: 10.1111/j.1365-2214.2010.01140.x

19. Starc G, Popovic S, Đordic V, Ostojic S, Milanovic SM, Kujundzic E, et al. Differences in body height between the contemporary Western Balkan and revised manuscript. SM collected the data. DB overviewed previous studies and discussed the results. JG discussed the results. All authors contributed to the article and approved the submitted version. children and the WHO growth references core sample. Anthropol Noteb. (2019) 25:55-67.

20. Gardasevic J, Martinovic S, Vasiljevic I, Bubanja M, Malovic P, Vrevic E. Analysis of Trends in Anthropometric Characteristics of Montenegrin Young Men from Niksic from 1957 to 1969. Sport Mont. (2020) 18:55-9. doi: $10.26773 / \mathrm{smj} .200616$

21. Masanovic B, Martinovic S, Zoric G, Bacovic D, Mitrovic M, Vukotic M. Trends in Body Height, Body Weight, and Body Mass Index from 1979 to 1987: An Analysis of the Young Male Population from the Municipality of Cetinje. J Anthropol Sport Phys Educ. (2020) 4:3-7. doi: 10.26773/jaspe.200401

22. Vasiljevic I, Martinovic S, Gardasevic J, Bubanja M, Malovic P, Vrevic E, et al. Analysis of trends in anthropometric characteristics of Montenegrin recruits from Bar in period from 1979 to 1987. J Anthropol Sport Phys Educ. (2020) 4:3-7. doi: 10.26773/jaspe.200701

23. American College of Sports Medicine. ACSM's Health-Related Physical Fitness Assessment Manual. Boston, MA: Wolters Kluwer (2013).

24. World Health Organization. Nutrition Landscape Information System (NLIS) Country Profile Indicators: Interpretation Guide. Geneva: WHO press (2010).

25. Schonbeck Y, Talma H, van Dommelen P, Bakker B, Buitendijk SE, HiraSing RA, et al. The world's tallest nation has stopped growing taller: the height of Dutch children from 1955 to 2009. Pediatr Res. (2013) 73:371-7. doi: 10.1038/pr.2012.189

26. Masanovic B, Gardasevic J, Arifi F. Relationship between foot length measurements and body height: a prospective regional study among adolescents in northern region of Kosovo. Anthropologie. (2019) 57:227-33. doi: 10.26720/anthro.18.01.23.1

27. Popovic S, Gardasevic J, Masanovic B, Arifi F, Bjelica D. Standing height and its estimation utilizing foot length measurements in adolescents from western region in Kosovo. Sport Mont. (2017) 15:3-7. doi: 10.26773/smj.2017.10.001

28. Federal Bureau of Statistics. National Structure of Population in SFR Yugoslavia. Statistical Office of the Republic of Serbia (1981). Retrieved from: https://pod2.stat.gov.rs/ObjavljenePublikacije/G1981/Pdf/G19814001. pdf

29. Monstat. Census of Population, Households and Dwellings in Montenegro 2011. (2011). Retrieved from: https://www.monstat.org/userfiles/file/popis2011/ saopstenje/saopstenje(1).pdf

30. Statistics Netherlands. Since 1981, People have Become Taller and Heavier. CBS (2019). Retrieved from: https://www.cbs.nl/en-gb/news/2019/48/since-1981people-have-become-taller-and-heavier

31. Gardasevic J, Vasiljevic I, Bjelica D, Popovic S. Analysis of nutrition of boys and girls, adolescents from Montenegro. J Phys Educ Sport. (2015) 15:702-4. doi: 10.7752/jpes.2015.04107

32. Bi C, Zhang F, Gu Y, Song Y, Cai X. Secular trend in the physical fitness of Xinjiang children and adolescents between 1985 and 2014. Int J Environ Res Public Health. (2020) 17:2195. doi: 10.3390/ijerph17072195

Conflict of Interest: The authors declare that the research was conducted in the absence of any commercial or financial relationships that could be construed as a potential conflict of interest.

Copyright (ङ 2020 Popovic, Masanovic, Martinovic, Bjelica and Gardasevic. This is an open-access article distributed under the terms of the Creative Commons Attribution License (CC BY). The use, distribution or reproduction in other forums is permitted, provided the original author(s) and the copyright owner(s) are credited and that the original publication in this journal is cited, in accordance with accepted academic practice. No use, distribution or reproduction is permitted which does not comply with these terms. 